\title{
APLIKASI VIRTUAL IKLAN PERUMAHAN DENGAN SISTEMAUGMENTED REALITY
}

\author{
Raden Wirawan \\ wirawan_raden@yahoo.com \\ Departemen Sistem Komputer, STMIK Bina Adinata, Bulukumba, Sulawesi Selatan
}

\begin{abstract}
ABSTRAK
Rumah merupakan kebutuhan manusia dan dapat dijadikan aset bisnis sehingga bisnis perumahan berkembang dengan pesat. Saat ini iklan perumahan biasanya melalui media cetak maupun promosi secara langsung yang kebanyakan dalam bentuk dua Dimensi (2D). Augmented Reality (AR) adalah suatu lingkungan yang memasukkan objek virtual 3D ke dalam lingkungan nyata. Dengan adanya program Augmented Reality sistem marketing perumahan dapat mempromosikan rumah dalam bentuk tiga dimensi (3D) dan membawa maket perumahan dalam bentuk 3D dimana objek rumah dapat di zoom in , zoom out, rotasi secara vertical, rotasi secara horizontal dan terdapat denah untuk tiap rumah serta informasi mengenai rumah tersebut. Melalui aplikasi Augmented Reality ini penulis berharap dapat memberi pengetahuan lebih kepada pembaca dan bisa membantu para pelaku bisnis properti pada umumnya, khususnya para sales dalam mempromosikan rumah dalam bentuk virtual 3D. Hasil penelitian ini menunjukkan bahwa penerapan teknologi Augmented Reality dapat diaplikasikan pada brosur perumahan dan dapat menarik perhatian pelanggan karena lebih mudah dalam memberikan informasi mengenai model rumah yang ditawarkan pada brosur perumahan.
\end{abstract}

Kata Kunci : Augmented Reality, Iklan Perumahan, Virtual 3D

\section{Pendahuluan}

Perkembangan teknologi multimedia yang semakin hari semakin canggih menuntut manusia untuk mampu menyelesaikan berbagai permasalahan yang kompleks. Untuk itu diperlukan berbagai macam penyelesaian-penyelesaian yang baru, efektif dan efisien. Salah satunya adalah penggunaan teknologi Augmented reality.

Dengan berkembangnya teknologi, kemudahan manusia dapat dilihat seperti dalam bidang properti, dimana perancangan bangunan yang tidak lagi menggunakan sistem manual. Beberapa aplikasi sudah banyak dikembangkan untuk membantu menyelesaikan pekerjaan manusia, seperti aplikasi CAD yang banyak digunakan untuk merancang desain bangunan. Selain itu ada pula aplikasi $3 D$ yang banyak digunakan untuk mendesain objek visual tigadimensi. Selain pada tahapan desain dan perancangan, pada segmen property tidakkalah pentingnya aspek pemasaran. Pada aspek pemasaran kini juga berkembang dari tahun ke tahun. Dimana yang biasa digunakan adalah brosur atau panflet, kini sudah banyak yang beralih keminiatur/maket yang mana objek yang akan di pasarkan dibuat sedemikian rupa sehingga hamper mendekati tampilan objek yang sesungguhnya atau yang biasa di sebut Virtual 3D [1][2].

Augmented Reality (AR) adalah suatu lingkungan yang memasukkan objek virtual 3D kedalam lingkungan nyata. Secara umum, Augmented Reality adalah menggabungkan dunia nyata dan virtual, bersifat interaktif secara real-time, bentuknya merupakan animasi 3D dan saling berinteraksi antara User dan AR itu sendiri. Perkembangan Augmented Reality yang sangat pesat memungkinkan pengembangan di berbagai bidang termasuk media periklanan. Saat ini, banyak literatur yang menunjukkan kemungkinan penggunaan AR di bidang media periklanan sebagai strategi pemasaran dan pengenalan produk kepada konsumen seperti brosur perumahan, apartemen, dan produk-produk lainnya yang akan dipublikasikan [3][4].

Rumah merupakan kebutuhan yang mutlak untuk manusia. Selain sebagai tempat tinggal, rumah juga dapat dijadikan asset bisnis yang menguntungkan sehingga bisnis perumahan berkembang dengan sangat pesat. Dalam aktifitas promosi terdapat dua cara yaitu promosi secara langsung yang menggunakan maket dan promosi yang tidak langsung menggunakan media cetak dan website sebagai media periklanannya. Promosi secara langsung biasa dilakukan oleh salesman/salesgirl perumahan , untuk mempromosikannya biasa salesman/salesgirl membawa brosur rumah namun tidak ada maket perumahan yang asli, sebab maket perumahan yang besar tidak memungkinkan untukdibawa-bawa oleh salesman/salesgirl. Alangkah baiknya apabila promosi dapat menggunakan objek berbentuk tigadimensi yang dapat dibawa kemana-mana untuk mendapatkan minat lebih dari konsumen [1][2]. Berdasarkan permasalahan yang ada menjadi pertimbangan bagi penulis untuk merancang sebuah aplikasi virtual iklan perumahan dengan menggunakan sistem augmented reality. 


\section{Metode}

\subsection{Perancangan proses}

Tahap perancangan dimulai dengan pembuatan flowchart Aplikasi AR. Flowchart aplikasi tersebut sebagai berikut.

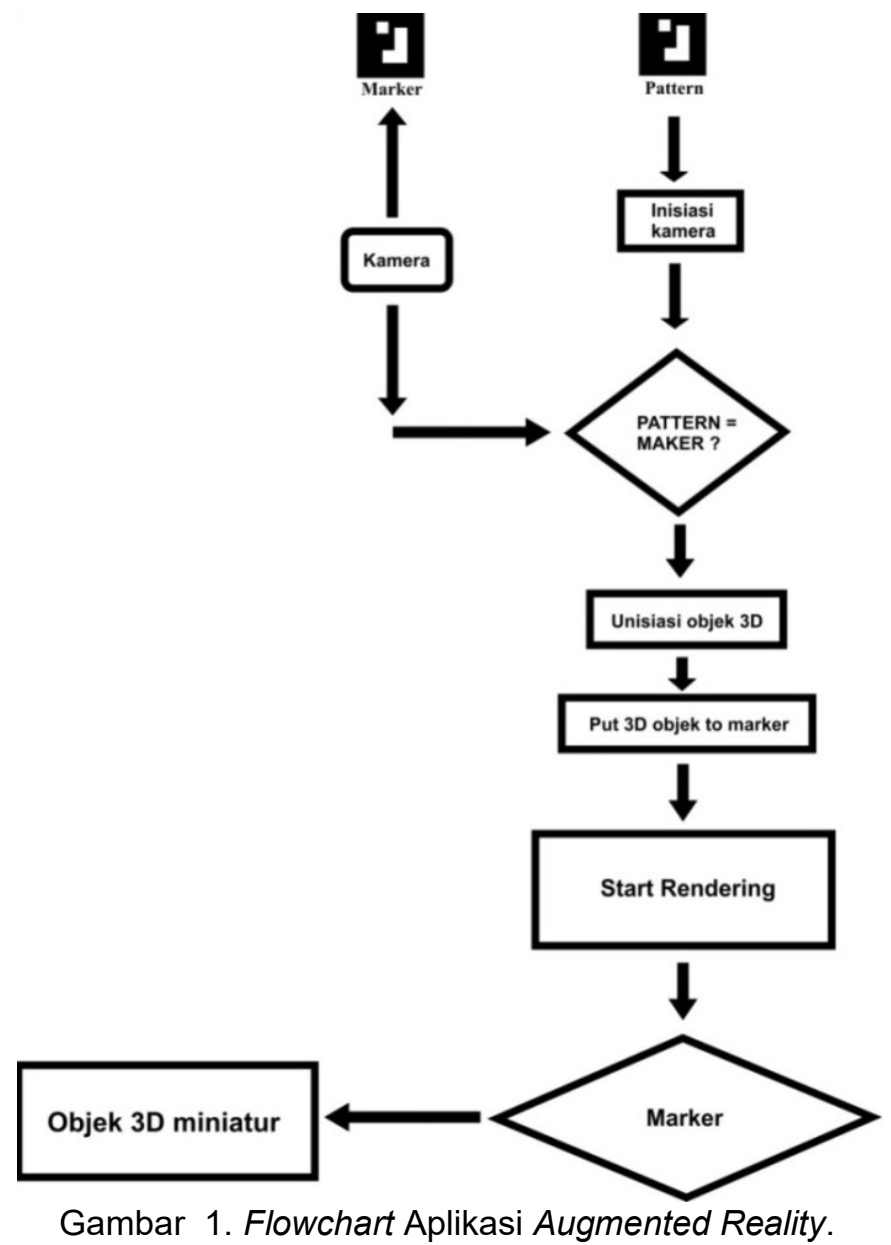

Gambar 1 mejelaskan bahwa Marker yang akan di baca oleh kamera dan diinisialisasi sesuai dengan pattern yang telah dibuat.Aplikasi akan menginilisiasi gambar 3D sesuai dengan pattern dan memanggilnya ke atas marker. Kemudian Aplikasi akan memulai merendering model atau objek 3D ke atas marker.

Marker biasanya merupakan ilustrasi hitam dan putih persegi dengan batas hitam tebal dan latar belakang putih . Komputer akan mengenali posisi dan orientasi marker dan menciptakan dunia virtual 3D yaitu titik $(0,0,0)$ dan 3 sumbu yaitu X,Y,dan Z. Marker Based Tracking ini sudah lama dikembangkan sejak tahun 80 an dan pada awal 90 an mulai dikembangkan untuk penggunaan Augmented Reality[3][5].

\subsection{Pembuatan model Objek 3D}

Pembuatan Model 3D dilakukan dengan membuat penggambaran awal objek berupa 2D (2 dimensi) yang akan menghasilkan objek atau gambar 3D dengan menggunakan tampilan perspektif. Pembuatan model menggunakan aplikasi ArchiCAD sebagai software dalam membuat atau mendesain model rumah. Setelah pembuatan model dena Export file ArchiCAD, dimana pada tahap ini file yang berada pada applikasi ArchiCAD disimpan ke dalam bentuk file *.3ds. Pada tahap ini model yang telah dibuat di export ke dalam format Ogre Scene ( ${ }^{*}$.SCENE) yang nantinya akan ditampilkan dengan menggunakan aplikasi Augmented Reality yang telah dibuat. Untuk cara export filenya dengan klik logo 3ds max yang ada di sudut kiri bagian atas, kemudian pilih "export" maka akan muncul kotak dialog "Select File to Export" lalu pilih Ogre Scene (*.SCENE) dan klik "Save" untuk mengakhisri tahap export file tersebut [6]. 


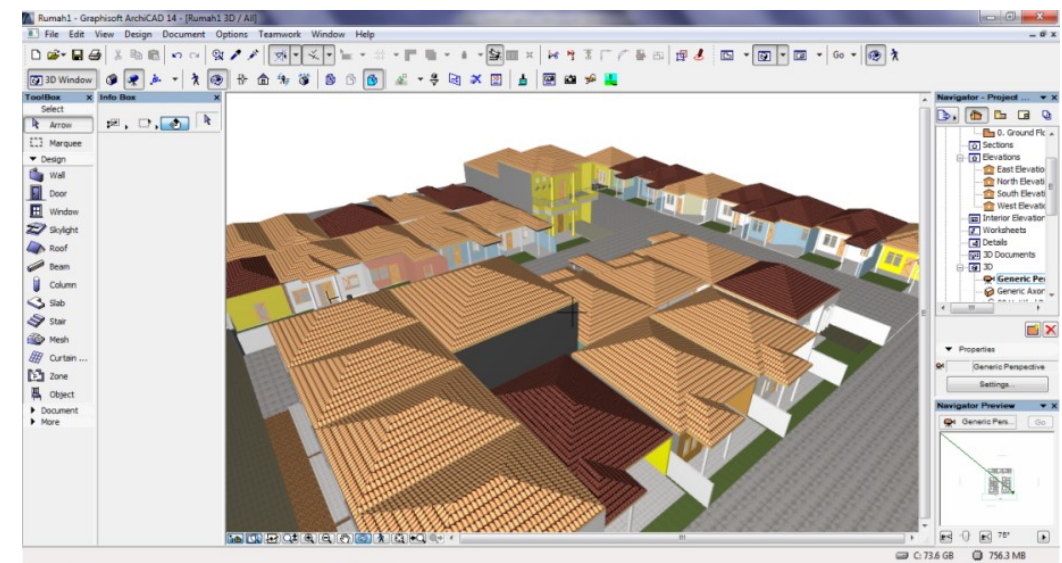

Gambar 2. Tampilan dalam bentuk 3D pada program ArchiCAD.

\subsection{Pembuatan marker dan brosur}

Pembuatan marker di buat dengan menggunakan aplikasi Corel Draw.

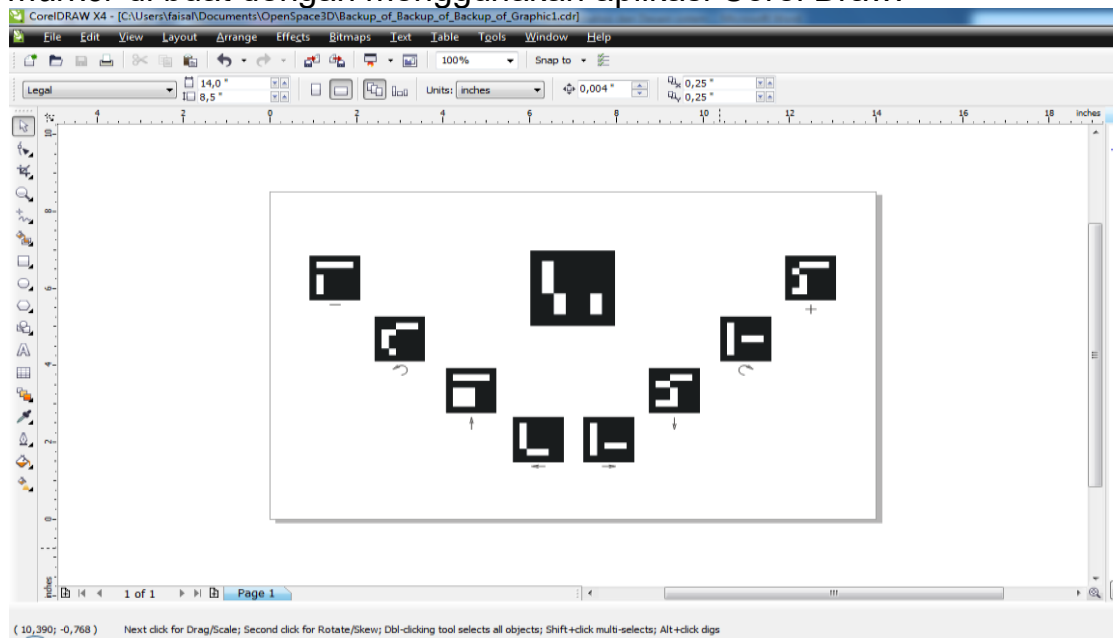

Gambar 3. Pembuatan Marker

Pertama, dibuat terlebih dulu kotak-kotak berwarna hitam. Kedua, membuat pola-pola warna putih didalam kotak hitam yang ada sesuai dengan pola marker yang akan dipakai pada Openspace3D.Selanjutnya mendesain brosur yang disisipkan marker di dalamnya.

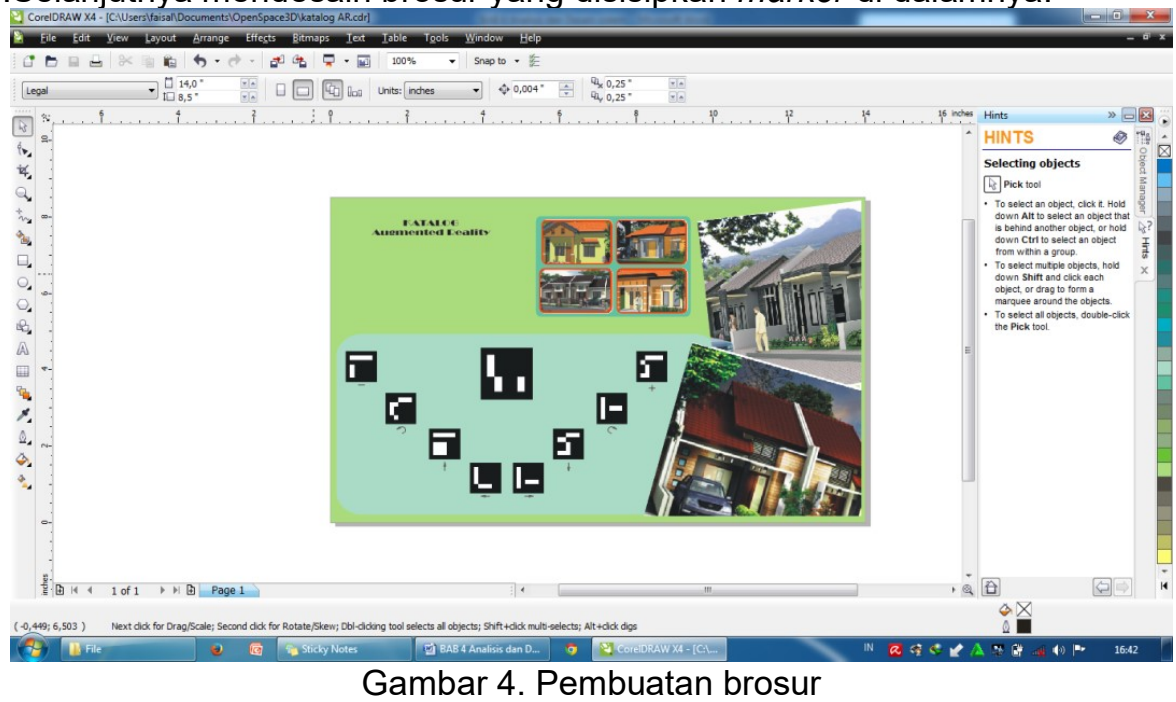

Pada gambar 4 terlihat brosur yang telah disisipkan marker, dimana marker tersebut akan menjadi penanda dalam menampilkan objek 3D dalam aplikasi Augmented Reality. 


\section{Hasil Dan Pembahasan}

\subsection{Implementasi Aplikasi Openspace3D}

Pada perancangan objek 3D menggunakan software modeling ArchiCAD dan 3Ds Max di exsport ke dalam format * .SCENE. file model objek 3D tersebut dimasukkan ke dalam folder aplikasi C:IUsersIfaisalIDocuments|OpenSpace3DI01 agar dapat di import kedalam aplikasi Openspace3D. Aplikasi Openspace3D mempunyai id marker yang tersedia sebanyak 1022 id [6]. Setelah selesai pada tahap inisialisasi, maka dilakukan proses render untuk pendeteksian marker.

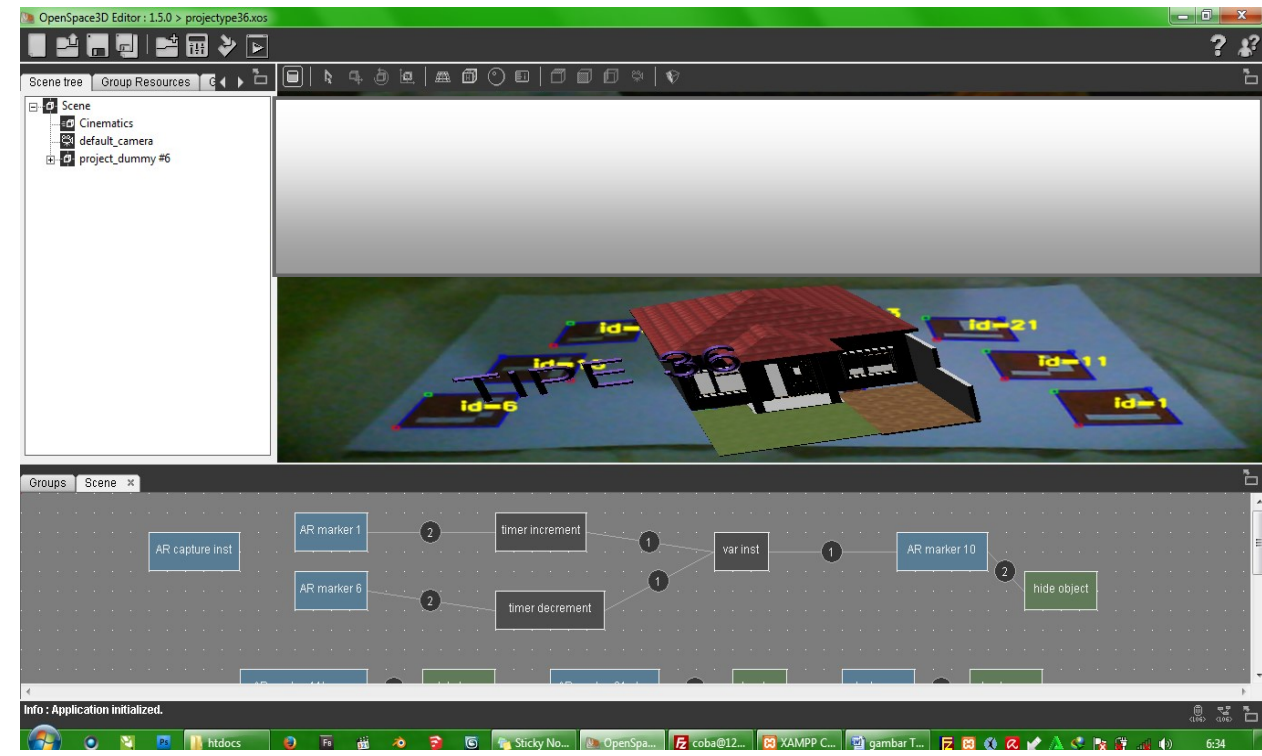

Gambar 5. Proses Rendering untuk rumah tipe 36

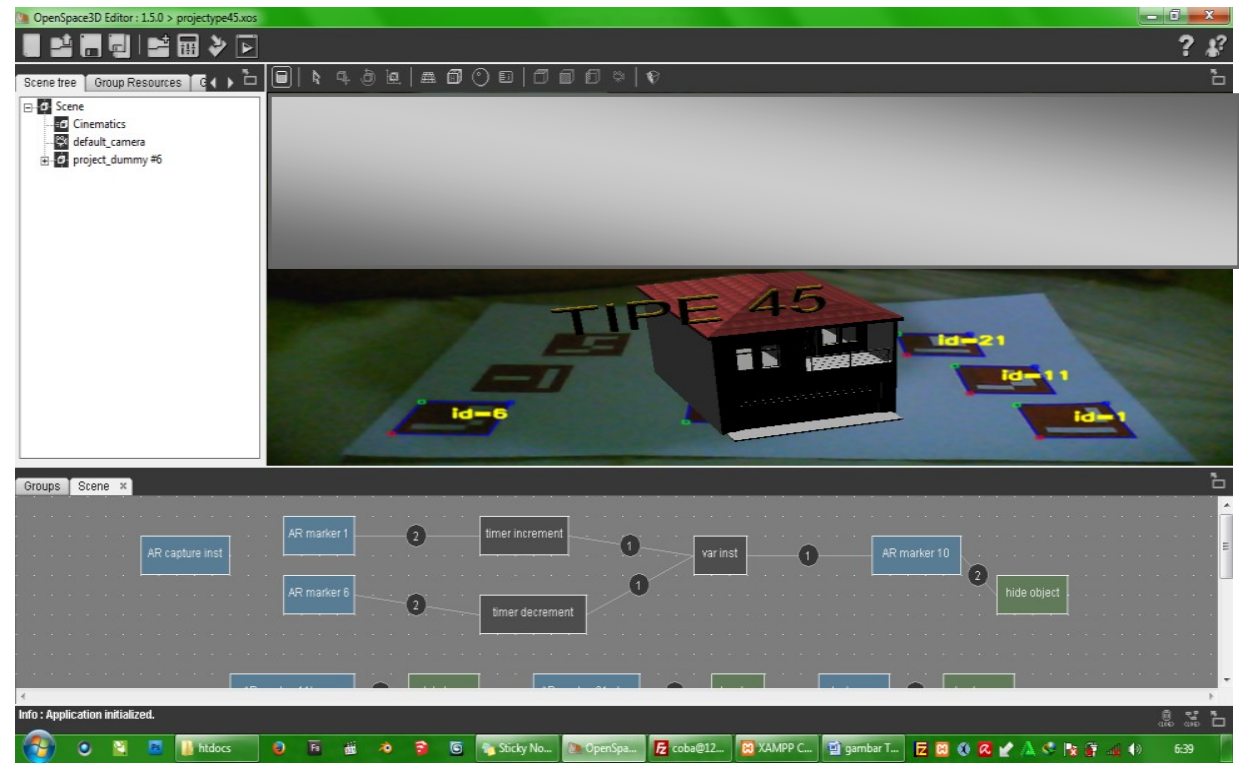

Gambar 6. Proses Rendering untuk rumah tipe 45

\subsection{Pengujian Marker}

Pengujian ini dilakukan untuk menguji jenis pola marker yang dapat dikenali kamera dengan baik, yang terdiri dari marker utama dan beberapa jenis pola marker tambahan sebagai kasus pengujian. 
Tabel 1. Hasil pengujian marker

\begin{tabular}{|c|c|c|c|}
\hline No. & Marker & Deskripsi & Hasil \\
\hline 1. & & $\begin{array}{l}\text { Id marker 10, } \\
\text { Marker Utama }\end{array}$ & $\begin{array}{l}\text { Terdeteksi,dapat } \\
\text { menampilkan objek } \\
\text { 3D perumahan }\end{array}$ \\
\hline 2. & & $\begin{array}{lr}\text { Id marker } 1, \text { Marker yang } \\
\text { berfungsi } & \text { untuk } \\
\text { memperkecil } & \text { tampilan } \\
\text { objek. } & \end{array}$ & $\begin{array}{l}\text { Terdeteksi,dapat } \\
\text { memperkecil } \\
\text { tampilan objek 3D. }\end{array}$ \\
\hline 3. & & $\begin{array}{lr}\text { Id marker 6, } & \text { Marker yang } \\
\text { berfungsi } & \text { untuk } \\
\text { memperbesar } & \text { tampilan } \\
\text { objek. } & \end{array}$ & $\begin{array}{l}\text { Terdeteksi,dapat } \\
\text { memperbesar } \\
\text { tampilan objek 3D. }\end{array}$ \\
\hline 4. & & $\begin{array}{l}\text { Id marker } 11, \text { Marker } \\
\text { yang berfungsi untuk } \\
\text { merotasi ke kiri tampilan } \\
\text { objek. }\end{array}$ & $\begin{array}{l}\text { Terdeteksi,dapat } \\
\text { merotasi ke kiri } \\
\text { tampilan objek 3D }\end{array}$ \\
\hline 5. & & $\begin{array}{l}\text { Id marker 16, } \\
\text { yang berfungsi } \\
\text { merotasi ke } \\
\text { mantuk } \\
\text { tampilan objek. }\end{array}$ & $\begin{array}{l}\text { Terdeteksi,dapat } \\
\text { merotasi ke kanan } \\
\text { tampilan objek 3D }\end{array}$ \\
\hline 6. & & $\begin{array}{l}\text { Id marker 21, Marker } \\
\text { yang berfungsi untuk } \\
\text { membalik tampilan objek } \\
\text { ke atas. }\end{array}$ & $\begin{array}{l}\text { Terdeteksi,dapat } \\
\text { membalik tampilan } \\
\text { objek 3D ke atas }\end{array}$ \\
\hline 7. & & $\begin{array}{l}\text { Id marker 26, Marker } \\
\text { yang berfungsi untuk } \\
\text { membalik tampilan objek } \\
\text { ke bawah. }\end{array}$ & $\begin{array}{l}\text { Terdeteksi,dapat } \\
\text { membalik tampilan } \\
\text { objek 3D ke bawah. }\end{array}$ \\
\hline 8. & & $\begin{array}{l}\text { Id marker } 3, \text { Marker yang } \\
\text { berfungsi untuk } \\
\text { membalik tampilan objek } \\
\text { ke kiri. }\end{array}$ & $\begin{array}{l}\text { Terdeteksi,dapat } \\
\text { membalik tampilan } \\
\text { objek 3D ke kiri }\end{array}$ \\
\hline 9. & & $\begin{array}{l}\text { Id marker 4, Marker yang } \\
\text { berfungsi untuk } \\
\text { membalik tampilan objek } \\
\text { ke kanan. }\end{array}$ & $\begin{array}{l}\text { Terdeteksi,dapat } \\
\text { membalik tampilan } \\
\text { objek 3D ke kanan }\end{array}$ \\
\hline
\end{tabular}




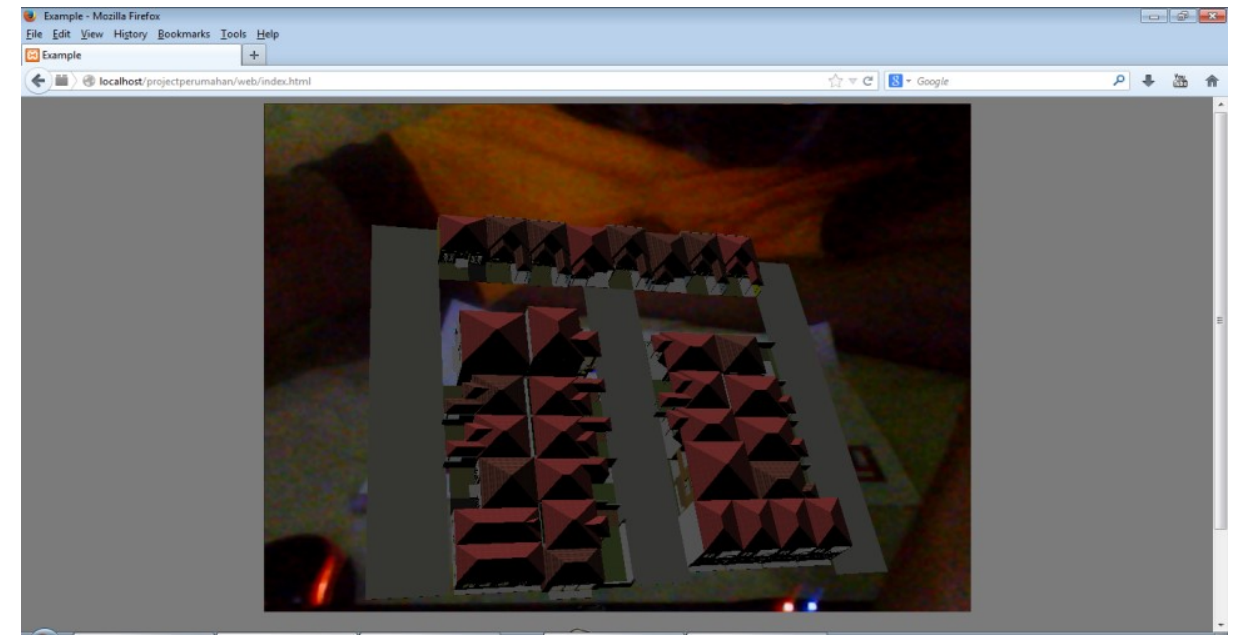

Gambar 7. Hasil pengujian marker untuk menampilkan keseluruhan perumahan

\subsection{Pengujian Webcam (Kamera)}

Pada Pengujian ini dilakukan untuk menguji jarak dan sudut pandang (kemiringan) kamera pada saat menangkap marker pada brosur, yang terdiri dari enam kali pengujian. Pada setiap pengujian memiliki ukuran dan kompleksitas pola marker yang berbeda-beda

Tabel 2. Tabel Hasil Pengujian Webcam (kamera).

\begin{tabular}{|c|c|c|c|c|}
\hline \multicolumn{2}{|c|}{ Marker } & \multicolumn{2}{|c|}{ Jarak antara Kamera dan Marker } & Kemiringan \\
\hline Ukuran $(\mathrm{cm})$ & Kompleksitas & Terpendek $(\mathrm{cm})$ & Terjauh $(\mathrm{cm})$ & Minimum $\left.{ }^{0}\right)$ \\
\hline 3 & Sederhana & 15 & 50 & 80 \\
\hline 5 & Kompleks & 20 & 65 & 88 \\
\hline
\end{tabular}

Berdasarkan tabel 2 yang terdiri dari beberapa jenis marker persegi dengan ukuran yang berbeda (dalam satuan sentimeter). Hasil yang didapatkan dengan menempatkan marker dilantai dan menggerakkan kamera dengan kemiringan (dalam satuan derajat) dan jarak yang berbeda sampai benda virtual pada marker menghilang. Dari tabel tersebut dapat disimpulkan bahwa semakin besar ukuran pola marker, semakin jauh pula pola dapat dideteksi dan kemiringan minimum semakin besar.

\section{Kesimpulan dan Saran}

Berdasarkan hasil penelitian yang telah dilakukan penulis maka dapat disimpulkan bahwa dengan adanya aplikasi virtual iklan perumahan dengan sistem augmented reality ini memudahkan marketing dan sales perumahan dalam memberi informasi mengenai iklan perumahan kepada pelanggan dengan tampilan objek 3D yang lebih menarik.

Untuk pengembangan teknologi Augmented Reality selanjutnya, diharapkan dapat meningkatkan kualitas efek 3D dan pemberian animasi agar obyek yang telah dirender dapat menampilkan objek yang lebih nyata.

\section{Datar pustaka}

[1] Chafied, Muchammad. 2010. Brosur Interaktif Berbasis Augmented Reality.Institut Teknologi Sepuluh November: Surabaya.

[2] Zamroni, Muhammad. 2012. Pengertian dan jenis-jenis periklanan, diakses tanggal 15 Juni 2017.

[3] Wirawan, Raden dkk. 2016. Aplikasi Augmented Reality pada Sistem Informasi Smart Building. JNTETI. Vol. 5 No. 3 . 2016

[4] Rekimoto J., 2005. "Matrix : A Real-Time Object Identification and Registration Method for Augmented Reality", Proceedings of the third Asia Pacific on computer-human interactions, Kangawa Japan, p. 63-98.

[5] Kustiawan, Iwan. 2008. Tsunami Augmented Reality: Interaksi Bebasis Marker sebagai Pointer. Bandung: ITB.

[6] Anugrah, Willy. 2012. Implementasi Augmented Reality Pada Pemasaran Rumah Bogor Nirwana Residence Menggunakan Blender dan OpenSpace3D. Universitas Gunadarma. 